\title{
Osteonecrosis of the jaw associated with everolimus: A case report
}

\author{
DAIGO YAMAMOTO ${ }^{1}$, YU TSUBOTA ${ }^{1}$, TOSHIKI UTSUNOMIYA ${ }^{2}$, NORIKO SUEOKA ${ }^{1}$, \\ AIKO UEDA $^{1}$, KAYOKO ENDO ${ }^{1,3}$, KATSUHIRO YOSHIKAWA $^{1}$ and MASANORI KON ${ }^{1,3}$ \\ Departments of ${ }^{1}$ Surgery and ${ }^{2}$ Otorhinology, Kansai Medical University Medical Center, Moriguchi, Osaka 570-8507; \\ ${ }^{3}$ Department of Surgery, Kansai Medical University-Affiliated to Hirakata Hospital, Hirakata, Osaka 573-1191, Japan
}

Received December 16, 2015; Accepted April 4, 2016

DOI: $10.3892 /$ mco.2016.1100

\begin{abstract}
Everolimus, a mammalian target of rapamycin inhibitor, has recently been approved for the treatment of metastatic estrogen receptor-positive breast cancer, at a daily dose of $10 \mathrm{mg}$ in combination with exemestane. Osteonecrosis of the jaw $(\mathrm{ONJ})$ is a rare but severe condition, characterized by exposed necrotic bone, and is associated with various drugs that are often used to treat advanced malignancies. We herein report the case of a patient with breast cancer who developed ONJ during treatment with everolimus, which improved after discontinuation of the drug. To the best of our knowledge, this is the first reported case of everolimus-associated ONJ in a patient receiving everolimus for metastatic breast cancer. In 2014, an 80-year-old woman was started on treatment with everolimus and exemestane for stage IIB estrogen receptor-positive breast cancer. Within 2 months, the left side of her face became edematous, with localized heat and tenderness of the left mandibular region and a 3-mm round area of exposed bone. There was purulent discharge and the surrounding gingiva was edematous and erythematous. The left mandible exhibited a low signal intensity area on T1-weighted magnetic resonance imaging. Treatment was discontinued and ONJ showed improvement after 2 months. Therefore, when prescribing everolimus for metastatic breast cancer, oncologists should be aware of the possibility of ONJ as a complication.
\end{abstract}

\section{Introduction}

Breast cancer $(\mathrm{BC})$ is the most common cancer affecting women worldwide and is the second leading cause of cancer-related mortality in women (1-3). Approximately $30 \%$ of all patients with $\mathrm{BC}$ develop metastasis, with a mean survival time from the diagnosis of recurrence of 18-30 months (1-4). Therefore, treatment provided to patients with metastatic BC (MBC)

Correspondence to: Dr Daigo Yamamoto, Department of Surgery, Kansai Medical University Medical Center, 10-15 Fumizono-cho, Moriguchi, Osaka 570-8507, Japan

E-mail: yamamotd@takii.kmu.ac.jp

Key words: breast cancer, osteonecrosis of the jaw, everolimus aims to prolong survival, while relieving symptoms and maintaining a good quality of life.

Aberrations of the phosphoinositide 3-kinase/protein kinase $\mathrm{B} / \mathrm{mammalian}$ target of rapamycin (PI3K/AKT/mTOR) pathway are common in BC, and increased PI3K/AKT/mTOR signaling is associated with resistance to hormone therapy and human epidermal growth factor receptor 2 (HER2)-targeted therapy (5). Based on results of the Breast Cancer Trials of Oral Everolimus-2 (BOLERO-2) study (5), the mTOR inhibitor everolimus (combined with exemestane) has been approved for the treatment of advanced hormone receptor-positive/HER2-negative BC that has shown progression with prior non-steroidal aromatase inhibitor therapy. Osteonecrosis of the jaw (ONJ) is a serious condition characterized by exposure of necrotic bone. Although ONJ is rare, it is associated with various drugs that are often used to treat patients with advanced malignancies $(6,7)$. ONJ associated with antiresorptive agents is most often found in patients who are on bisphosphonate therapy. However, ONJ caused by molecular-targeted (anti-angiogenic) agents, such as sunitinib (a multikinase inhibitor) and bevacizumab [a monoclonal antibody targeting vascular endothelial growth factor (VEGF)], has recently been reported in patients who have never received bisphosphonates (8-10). We herein report the first case of ONJ in a patient receiving treatment with everolimus for $\mathrm{MBC}$.

\section{Case presentation}

In 2001, a 67-year-old woman underwent mastectomy and axillary lymph node dissection for stage IIB estrogen receptor-positive cancer of the right breast. In March, 2011, the patient developed metastases to the lymph nodes and chest wall. She consecutively received capecitabine and two lines of hormone therapy, including tamoxifen and fulvestrant. In December, 2014, administration of everolimus (10 mg/day) plus exemestane ( $25 \mathrm{mg} /$ day) was initiated. After 2 months, the left side of her face became edematous, with localized heat and tenderness in the left mandibular region, as well as a round 3-mm area of exposed bone. There was also purulent discharge, and the surrounding gingiva was edematous and erythematous. On T1-weighted magnetic resonance imaging, a low signal intensity area was identified in the left mandible. The patient had no relevant past dental history, such as tooth extraction. To rule out metastasis, an incisional biopsy specimen was obtained by an otolaryngologist. The pathological 


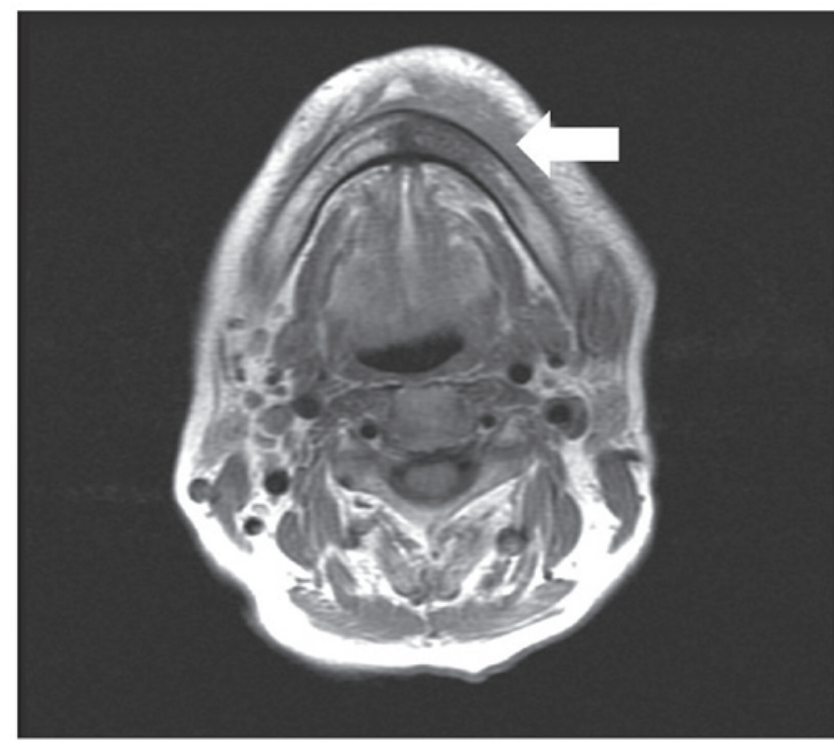

Figure 1. T1-weighted image showing a hypointense area in the left mandible (white arrow), corresponding to focal osteonecrosis.

examination revealed chronic non-specific inflammatory cells with no evidence of metastasis; thus, ONJ was diagnosed. Treatment with everolimus and exemestane was discontinued and cephalosporin was administered for 2 weeks. The acute inflammation gradually resolved and the exposed bone showed improvement after 2 months.

\section{Discussion}

The first case of ONJ was described in 2003 (11). Bisphosphonates and other antiresorptive medications are associated with a risk of ONJ, which is a complex condition involving multiple tissue and cellular responses to wound healing and/or infection. Patients with ONJ develop inflammation with exposure of the bone affecting the mandible, maxilla, or both, in the absence of previous radiation therapy or metastasis. Cancer patients have been reported to be at a higher risk for ONJ, with a prevalence of $1.5 \%$. In Australia, an average prevalence of $1.15 \%$ was reported in cancer patients, reaching $7.8 \%$ in those undergoing dental work $(11,12)$. In another study, patients with myeloma had a prevalence nearly double $(55.9 \%)$ that of patients with BC (33.4\%) or prostate cancer (4.6\%), despite all three groups being treated for metastatic bone lesions with zoledronate or pamidronate by the same protocol (12).

ONJ may be easy to overlook at its onset (stage 0), since it presents with chronic inflammation of the gums and slow healing following tooth extraction or implant surgery; paresthesia, odontalgia, or lingual dysesthesia; loss of teeth that cannot be attributed to chronic periodontal disease; or periapical/periodontal fistula not associated with caries. Later stages (1-3) are characterized by necrosis of the jawbone, with yellowish-white areas, suppuration, fistulae in the oral cavity or externally to the skin, and bleeding. Our patient had stage 2 ONJ.

There have been recent reports on the possible association of ONJ with everolimus $(13,14)$. However, bisphosphonates were also administered to the patients in these reports, so the authors were unable to reach a definitive conclusion

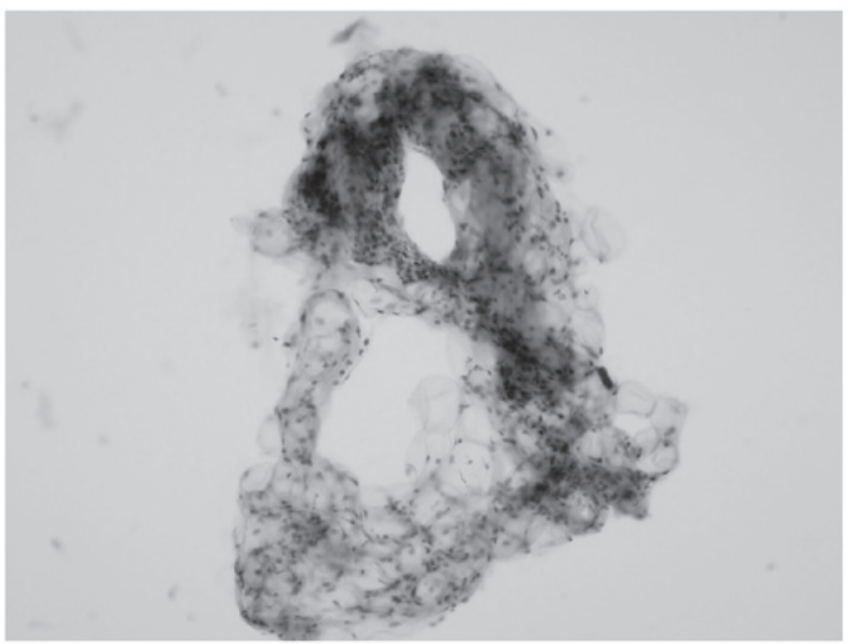

Figure 2. Microscopic examination revealed chronic non-specific inflammation. There was no evidence of malignancy.

regarding the cause of osteonecrosis. Therefore, to the best of our knowledge, this is the first reported case of ONJ caused by everolimus. Everolimus inhibits the activity of mTOR, a serine/threonine kinase involved in cell growth and metabolism, resulting in a decrease of VEGF levels and inhibition of the growth and proliferation of tumor cells, endothelial cells, fibroblasts and blood vessels. Everolimus has been approved for the treatment of advanced BC, neuroendocrine tumors of pancreatic origin and advanced renal cell carcinoma.

Preclinical studies in mouse models have demonstrated that inhibition of mTOR reduces the maturation and increases the apoptosis of osteoclasts $(15,16)$, which may be the mechanism underlying the occurrence of osteonecrosis associated with mTOR inhibitors.

There have also been reports of ONJ caused by sunitinib and bevacizumab. On histological examination, the vasculature is intact in ONJ lesions, despite the anti-angiogenic effect of drugs such as bisphosphonates, bevacizumab, sunitinib and everolimus $(8,10,17)$. Therefore, vascular impairment may not play a major role in the development of ONJ $(18,19)$ and further studies are required to elucidate the mechanism of $\mathrm{ONJ}$ in patients treated with everolimus.

In conclusion, attention to the possibility of $\mathrm{ONJ}$ is required when everolimus is used to treat patients with MBC.

Written consent was obtained from the patient for publication of this report and the related photos.

\section{References}

1. Guarneri V and Conte PF: The curability of breast cancer and the treatment of advanced disease. Eur J Nucl Med Mol Imaging 31 (Suppl 1): S149-S161, 2004.

2. Gonzalez-Angulo AM, Morales-Vasquez F and Hortobagyi GN: Overview of resistance to systemic therapy in patients with breast cancer. Adv Exp Med Biol 608: 1-22, 2007.

3. Cance WG, Carey LA, Calvo BF, Sartor C, Sawyer L, Moore DT, Rosenman J, Ollila DW and Graham M 2nd: Long-term outcome of neoadjuvant therapy for locally advanced breast carcinoma: Effective clinical downstaging allows breast preservation and predicts outstanding local control and survival. Ann Surg 236: 295-302; discussion 302-303, 2002.

4. American Cancer Society: Cancer Facts \& Figures 2014. American Cancer Society, Atlanta, 2014. 
5. Johnston SR: Enhancing endocrine therapy for hormone receptor-positive advanced breast cancer: Cotargeting signaling pathways. J Natl Cancer Inst 107: djv212, 2015.

6. Guarneri V, Miles D, Robert N, Diéras V, Glaspy J, Smith I, Thomssen C, Biganzoli L, Taran T and Conte P: Bevacizumab and osteonecrosis of the jaw: Incidence and association with bisphosphonate therapy in three large prospective trials in advanced breast cancer. Breast Cancer Res Treat 122: 181-188, 2010.

7. Watters AL, Hansen HJ, Williams T, Chou JF, Riedel E, Halpern J, Tunick S, Bohle G, Huryn JM and Estilo CL: Intravenous bisphosphonate-related osteonecrosis of the jaw: Long-term follow-up of 109 patients. Oral Surg Oral Med Oral Pathol Oral Radiol 115: 192-200, 2013.

8. Santos-Silva AR, Belizário Rosa GA, Castro Júnior GD Dias RB, Prado Ribeiro AC and Brandão TB: Osteonecrosis of the mandible associated with bevacizumab therapy. Oral Surg Oral Med Oral Pathol Oral Radiol 115: e32-e36, 2013.

9. Christodoulou C, Pervena A, Klouvas G, Galani E, Falagas ME Tsakalos G, Visvikis A, Nikolakopoulou A, Acholos V, Karapanagiotidis G, et al: Combination of bisphosphonates and antiangiogenic factors induces osteonecrosis of the jaw more frequently than bisphosphonates alone. Oncology 76: 209-211, 2009.

10. Fleissig Y, Regev E and Lehman H: Sunitinib related osteonecrosis of jaw: A case report. Oral SurgOral Med Oral Pathol Oral Radiol 113: e1-e3, 2012.

11. Marx RE: Pamidronate (Aredia) and zoledronate (Zometa) induced avascular necrosis of the jaws: A growing epidemic J Oral Maxillofac Surg 61: 1115-1117, 2003.

12. Longato L, Cavalli L, Marcucci G, Metozzi A, Giusti F, Brandi ML and Piscitelli P. Osteonecrosis of the jaw in a patient with rheumatoid arthritis treated with an oral aminobisphosphonate: A clinical case report. Clin Cases Miner Bone Metab 10: 139-141, 2013
13. Giancola F, Campisi G, Lo Russo L, Muzio LL and Di Fede O: Osteonecrosis of the jaw related to everolimus and bisphosphonate: A unique case report? Ann Stomatol (Roma) 4 (Suppl 2): 20-21, 2013.

14. Kim DW, Jung YS, Park HS and Jung HD: Osteonecrosis of the jaw related to everolimus: A case report. Br J Oral Maxillofac Surg 51: e302-e304, 2013.

15. Kneissel M, Luong-Nguyen NH, Baptist M, Cortesi R, Zumstein-Mecker S, Kossida S, O'Reilly T, Lane H and Susa M: Everolimus suppresses cancellous bone loss, bone resorption, and cathepsin K expression by osteoclasts. Bone 35: 1144-1156, 2004.

16. Allegra A, Alonci A, Penna G, Granata A, Nastro Siniscalchi E, Oteri G, Loddo S, Teti D, Cicciù D, De Ponte FS and Musolino C: Bisphosphonates induce apoptosis of circulating endothelial cells in multiple myeloma patients and in subjects with bisphosphonate-induced osteonecrosis of the jaws. Acta Haematol 124: 79-85, 2010.

17. Lane HA, Wood JM, McSheehy PM, Allegrini PR, Boulay A, Brueggen J, Littlewood-Evans A, Maira SM, Martiny-Baron G, Schnell CR, et al: mTOR inhibitor RAD001 (everolimus) has antiangiogenic/vascular properties distinct from a VEGFR tyrosine kinase inhibitor. Clin Cancer Res 15: 1612-1622, 2009.

18. Yamashita J, McCauley LK and Van Poznak C: Updates on osteonecrosis of the jaw. Curr Opin Support Palliat Care 4: 200-206, 2010.

19. Troeltzsch M, Woodlock T, Kriegelstein S, Steiner T, Messlinger K and Troeltzsch M: Physiology and pharmacology of nonbisphosphonate drugs implicated in osteonecrosis of the jaw. J Can Dent Assoc 78: c85, 2012. 